PDFlib PLOP: PDF Linearization, Optimization, Protection

Page inserted by evaluation version www.pdflib.com - sales@pdflib.com 


\title{
The Influence of the Loading Mode on the Stress Distribution on the Connector Region of Metal-ceramic and All-ceramic Fixed Partial Denture
}

\author{
*Andréa Barreira Motta, †Luiz Carlos Pereira, \$Andréia R.C.C. da Cunha, \\ and §Fernando Pereira Duda
}

\begin{abstract}
*Department of Metallurgy and Materials Engineering and Prosthesis and Dental Materials Department, Federal University of Rio de Janeiro, PEMM/COPPE/UFRJ; †Department of Metallurgy and Materials Engineering, Federal University of Rio de Janeiro, PEMM/COPPE/UFRJ; $\neq$ Prosthesis and Dental Materials Department, Rio de Janeiro State University; and $\S$ Department of Mechanical Engineering, Federal University of Rio de Janeiro, PEM/COPPE/UFRJ, Rio de Janeiro, Brazil
\end{abstract}

\begin{abstract}
Studies pertaining to the mechanical behavior of fixed partial dentures (FPDs) frequently found the highest tensile stress values at the connector region when load is applied at the pontic central region. The connector region is considered the weakest point of the prosthesis with the greatest potential of fractures, regardless of the material used. This 2D finite element study compared the stress distribution on three-element all-ceramic and metalceramic FPDs with different loading conditions. Three FPD models were designed: (i) metal-ceramic FPD; (ii) allceramic FPD with the veneering porcelain only on the occlusal face; and (iii) all-ceramic FPD with the veneering porcelain on the occlusal and cervical face of the pontic. Loads of $100 \mathrm{~N}$ were applied following these simulations: (i) distributed on all working cusps; (ii) only on the abutment teeth; and (iii) only on the pontic. There is a significant change on the stress distribution and on the tensile
\end{abstract}

stress values when the load configuration is changed. The stress distribution from the load applied on the abutments was significantly better compared with the other two load simulations. When the loads were applied on the pontic and distributed on all working cusps, the highest tensile stress values appeared on the cervical region of the connectors between the abutments and the pontic. However, when the load was applied on the abutment teeth, the maximum tensile stress value significantly decreased and was located on the occlusal region of the connectors. In fact, the load applied on the pontic region does not simulate the clinical situation. Studies using this load configuration have overestimated the connector regions as having the highest probability of failures. Key Words: Finite element analysisFixed partial dentures-Stress analysis-Metal ceramic restorations-Stress fractures.
In spite of the increase in the use of all-ceramic fixed partial dentures (FPDs), metal-ceramic systems continue to be used due to their clinical longevity and biocompatibility (1). This kind of prosthesis is used mainly when a great number of teeth replacements

doi:10.1111/j.1525-1594.2008.00544.x

Received September 2007.

Address correspondence and reprint requests to Dra. Andréa Barreira Motta, Department of Metallurgy and Materials Engineering, Federal University of Rio de Janeiro, PEMM/COPPE/ UFRJ, Cid. Universitária-Centro de Tecnologia-Bloco F, sala F-210, Ilha do Fundão, Postal Code 68505, Rio de Janeiro, RJ 21941-970, Brazil. E-mail: amotta@metalmat.ufrj.br

Presented in part at the 4th Latin American Congress for Artificial Organs and Biomaterials held on August 8-11, 2006, in Caxambú, Brazil. are needed. The advantages of the metal-ceramic FPDs lie in their predictable structural performance, versatility, and cost. The advantages of all-ceramic FPD are the improved esthetic and the lower allergenic potential of the ceramic materials used as infrastructure (2).

Clinical studies present FPD longevity and the main causes for their failure. Olsson et al. (3) have reported that 91 and $83 \%$ of In-Ceram alumina short-spam FPDs had survived after 5 and 10 years, respectively. In contrast, for metal-ceramic FPDs, the survival rates found by Karlsson (4) revealed a 93\% success rate in a 10-year period, while Palmqvist and Swartz (5) reported a $79 \%$ success rate over an 18 - to 23-year period. Lindquist et al. (6) analyzed 26 FPDs and reported that the principal clinical reasons for 
the removal of an FPD are loss of retention or caries (seven cases), biomechanical (one case), and fracture of the infrastructure (one case). They stated that 10 years in service appears to be a survival breakpoint for extensive FPDs. This decrease in FPD survival rate after 10 years may be a result of material fatigue $(7,8)$ and/or a combination of biologic and biomechanical factors (9).

The failure rate of three-unit ceramic FPDs around connector areas between abutments and pontics has been reported to be relatively high (2). If the connector design is altered in maximum tensile regions, the stress distribution pattern can be changed to improve the survival rate of three-unit FPDs (10).

The connector regions have a narrow constriction for biologic and esthetic reasons, called cervical and occlusal embrasures, which act as stress concentrators (10). When the regions next to the embrasures were submitted to tensile components, the magnitude of local tensile stress increased significantly and reached the maximum tensile stress value at the embrasure tip $\left(\sigma_{\max }\right)$, which can be calculated from the geometric parameter $K_{\mathrm{t}}$ (stress concentration factor) $(11,12)$. The stress concentration factor $\left(K_{\mathrm{t}}\right)$ corresponds to the measure of stress intensity at the tip of the defect and can be calculated as $\sigma_{\mathrm{m}} / \sigma_{\mathrm{o}}$ ratio $\left(\sigma_{\mathrm{m}}\right.$ is the maximum local crack-tip stress and $\sigma_{\mathrm{o}}$ is the nominal stress) that is related to the defect length $(a)$ and radius of curvature of the defect tip $(\rho)$, according to Eq. $1(11,12)$. The $K_{\mathrm{t}}$ increases as the radius of curvature of the defect tip (embrasure) decreases:

$$
K_{t}=\sigma_{\mathrm{m}} / \sigma_{\mathrm{o}}=1+2(a / \rho)^{1 / 2}
$$

Some studies were realized to analyze the connector dimensions and to compare the materials used to FPDs fabrication. Argereau et al. (13) analyzed the influence of the connector size on the magnitude of strain by means of 3D finite element analyses (FEA). They applied a unidirectional axial force $(500 \mathrm{~N})$ to the pontic central region. The results showed that the maximum strain was always initiated practically in the center of the connector's cervical area.

Johanson et al. (14) recorded the dimensions of the metal infrastructure of metal-ceramic restorations under fabrication in dental laboratories. They analyzed 115 FPDs and found that the vertical dimensions of the connectors were greater in the anterior region (mean $4.4 \mathrm{~mm}$ ) than in the posterior region (mean $3.6 \mathrm{~mm}$ ). Ridwaan et al. (15) found results conspicuously lower in the posterior area, at 2.7 and $2.9 \mathrm{~mm}$ for maxillary and mandibular arches, respectively, although their widths of $3.6 \mathrm{~mm}$ were closer to the $4.0-\mathrm{mm}$ recommendations.
Kamposiora et al. (16) used a 2D finite element analysis (FEA) to study the stress distribution within three-unit FPDs constructed with different materials (Type III gold alloy, Dicor, and In-Ceram) and with different connector heights $(3.0$ and $4.0 \mathrm{~mm}$ ). The $10-\mathrm{MPa}$ load was centrally applied at the pontic region. The highest values of von Mises stresses were concentrated within the connectors; the greatest stresses occurred at the axial location of the connector. The stresses were $40-50 \%$ lower for $4.0-\mathrm{mm}$ connectors. The stress values within In-Ceram models were lower than the values found for the other two materials. The stress values represented a lower percentage of the ultimate strength of the material.

Research has shown that the connector is the weakest region of an FPD (2,10,13-17). However, most of this research applied loads at the center of the pontic. This loading mode is the same used to measure the strength resistance of a beam in a threepoint-bending test (12). Clinically, the load is distributed by the abutment teeth and the pontic. In some cases, the pontic was maintained in infra-occlusion (18).

The prediction of the survival rate for FPDs can be obtained by well-designed clinical studies; however, it is difficult to standardize the prosthesis designs to ensure realistic estimates of the survival time as a function of shape parameters. Model tests with actual specimens fabricated with teeth anatomic configuration may be a useful tool for the identification of the FPD behavior (19).

The purpose of this study was to analyze the effect of different loading conditions on the stress distribution in metal-ceramic and in all-ceramic FPDs designed with different geometries by using the finite element methodology. The maximum and mean stress values were used for the comparison of the results, as they are important for the failure criteria analyses.

\section{MATERIALS AND METHODS}

All external diameters of the reference natural teeth (mandibular second premolar and second molar, approved in June 28, 2005 by the Ethics Committee, CEP/UFRJ, MEMO No: 657/05, 105/5) were measured by a caliper rule. The teeth internal structures were measured with X-ray images. Those measures were used to design the sound structures of both abutments. Afterwards, dental preparations were done on each tooth with the AutoCad program (2004 version, Autodesk, Inc., Neuchatel, Switzerland) according to the details described by Shillinburg et al. (20). All the specific parts (Fig. 1), 


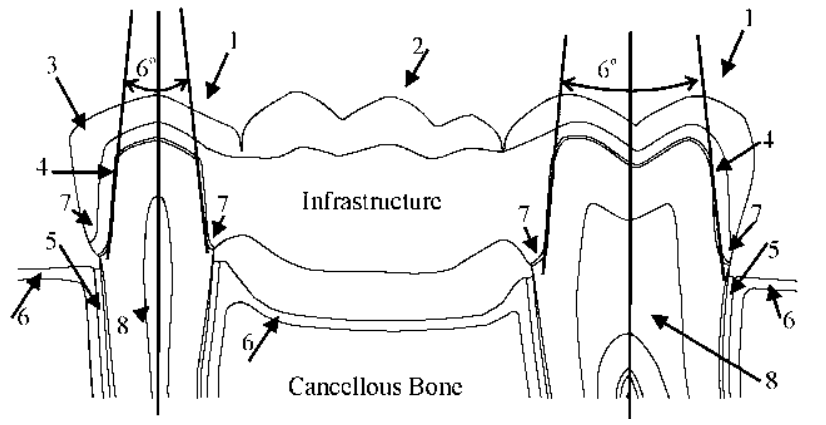

infrastructures (metal or ceramic), veneering porcelain, cement, and the pontic element (substituting the lost mandibular first molar), were designed with specific dimensions to generate different FPD models, as described below:

1 metal-ceramic FPD (MC-FPD; Fig. 2A);

2 all-ceramic FPD with veneering porcelain only on occlusal region (all-ceramic-O-FPD; Fig. 2B);

3 all-ceramic FPD with veneering porcelain on occlusal and cervical face of the pontic (allceramic-OC-FPD; Fig. 2C).

A 120-degree chamfer finishing line and a total axial taper of 6 degrees per abutment were used for the abutment teeth (Fig. 1). The periodontal ligament, and compact and cancellous bone were designed according to their normal anatomy (21) (Fig. 1). Each part was exported to an FEA program (ABAQUS CAE 6.5 version, Hibbit, Inc., Providence, RI, USA). All parts were considered
1 - Abutment Tooth

2 - Pontic

3 - Vencering Porcelain

4 - Cement

5 - Periodontal Ligament

6 - Cortical Bone

7 - Finishing Line

8 - Pulp
FIG. 1. FPD representation: each part and parameters.

homogeneous and isotropic and the elastic properties (elasticity modulus and Poisson's ratios) (22-25) attributed to them are in Table 1 . In relation to the boundary conditions, the encastre was always positioned at the base of the model to prevent rotation and translation.

One hundred-newton compressive loads were applied in an area of $0.5 \mathrm{~mm}^{2}$. The place of load application differs for each analysis:

1 Case a-distributed in all working cusps: physiologic load (Fig. 3A);

2 Case b-applied only on the abutment teeth: abutment load (Fig. 3B);

3 Case c-applied only on the pontic: pontic load (Fig. 3C).

The 2D model mesh had four-node-quadrilateral elements, and its size differs for each part according to the specific needs to obtain less distortion. The mesh can be visualized in Fig. 4.

A

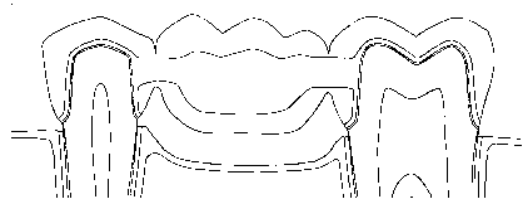

$\mathrm{B}$

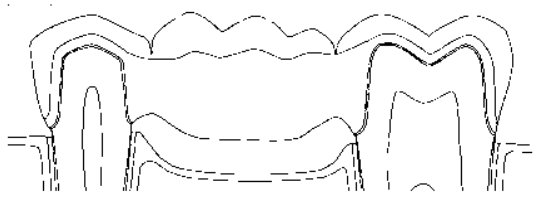

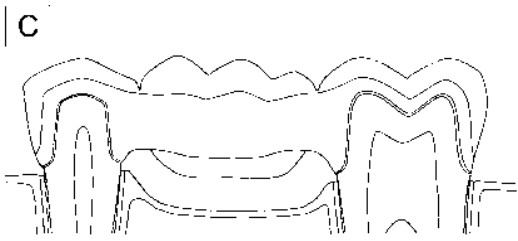

FIG. 2. Geometrical models: (A) metal-ceramic FPD; (B) all-ceramic-O-FPD; and (C) all-ceramic-OC-FPD.

TABLE 1. Mechanical properties of each tooth part

\begin{tabular}{lcc}
\hline Material & Elasticity modulus (E) (MPa) & Poisson's ratio (v) \\
\hline Dentin (22) & 18600 & 0.31 \\
Cement (22) & 18600 & 0.31 \\
Pulp (21) & 2.07 & 0.45 \\
Periodontal ligament (21) & 50 & 0.49 \\
Cancellous bone (21) & 345 & 0.3 \\
Compact bone (22) & 13800 & 0.26 \\
Veneering porcelain (23) & 68900 & 0.28 \\
Infrastructure (Ni-Cr) (22) & 205000 & 0.33 \\
Infrastructure (In-Ceram) (24) & 269000 & 0.3 \\
Cement zinc phosphate (25) & 13720 & 0.35 \\
Cement panavia (24) & 4040 & 0.35 \\
\hline
\end{tabular}




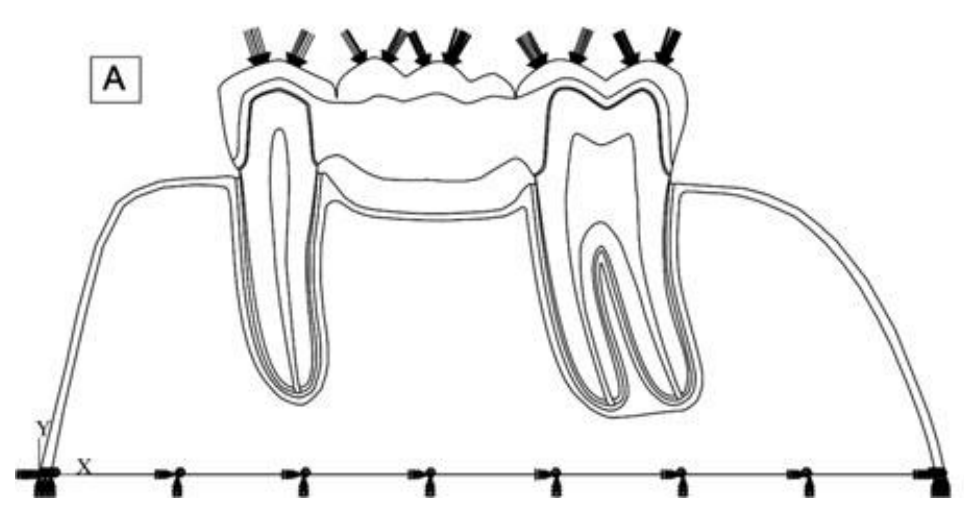

B
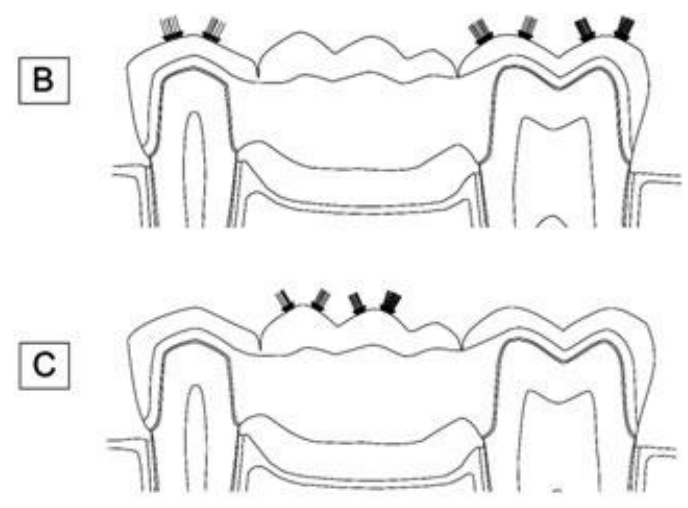

FIG. 3. Loading conditions: (A) load distributed in all working cusps: physiologic load; (B) load applied only on the abutment teeth: abutment load; and (C) load applied only on the pontic: pontic load.

The results were represented through figures (stress distributions), graphs, and table (stress values). In this study, special attention was dedicated to the maximum tensile stress values, as they have a higher potential to cause damage to FPD materials and dental tissues. The maximum and mean stress values were obtained from the results of principal stress at the nodes inside the selected regions (Fig. 5). The selected regions were the connector between the premolar tooth and the pontic (PM-con) and the connector between the molar tooth and the pontic (M-con).

\section{RESULTS}

Figure $6 \mathrm{~A}-\mathrm{C}$ shows the stress distribution found for each FPD design according to the loading condition. Figure 7 shows the maximum and mean stress values found for each model and region. In Table 2 the maximum and mean stress values for each model and loading condition are shown.

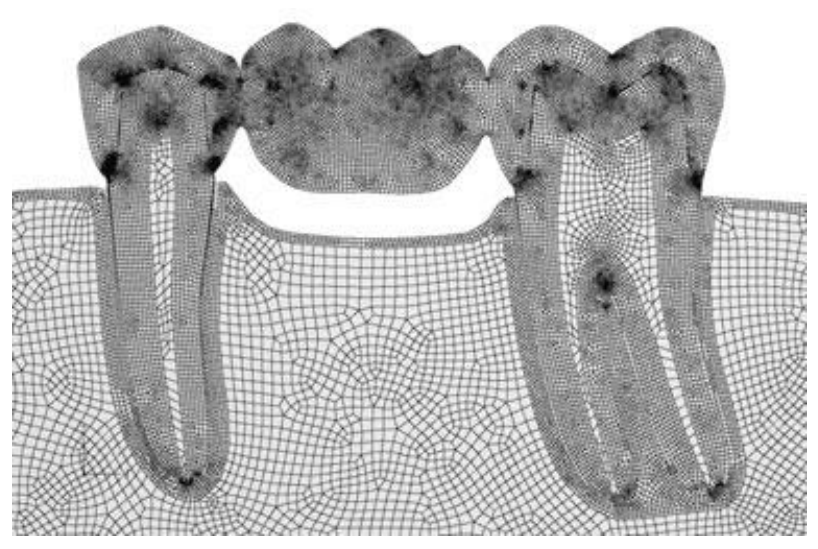

FIG. 4. FPD model mesh.

\section{Physiologic load}

Under the physiologic load (Fig. 6A), the highest principal stresses occurred on the cervical embrasure of the premolar and molar connectors, and the cervical region of the pontic. In the PM-con region, the all-ceramic-O-FPD produced the lowest stress value $(105 \mathrm{MPa})$. The all-ceramic-OC-FPD presented results $20 \%$ higher $(126 \mathrm{MPa})$ and the MC-FPD, 34\% higher (141 MPa) (Fig. 7A, Table 2). For the M-con region, the all-ceramic-O-FPD also had the lowest stress value $(78 \mathrm{MPa})$. However, the MC-FPD presented almost the same result with $79 \mathrm{MPa}$ (1\% higher), and the all-ceramic-OC-FPD presented values $27 \%$ higher (99 MPa) (Fig. 7B).

\section{Abutment load}

The resulting stress distribution from the load applied on the abutments (Fig. 6B) was significantly different compared with the other loading conditions (Fig. 6A,C). The highest values of tensile stress were found at the occlusal embrasure of both connectors. Besides, the greatest principal stresses were lower and limited to a small area for the three types of models under this load. For the PM-con, the tensile stress values found for the MC-FPD were $67 \%$ higher $(117 \mathrm{MPa})$ than the value found for the all-

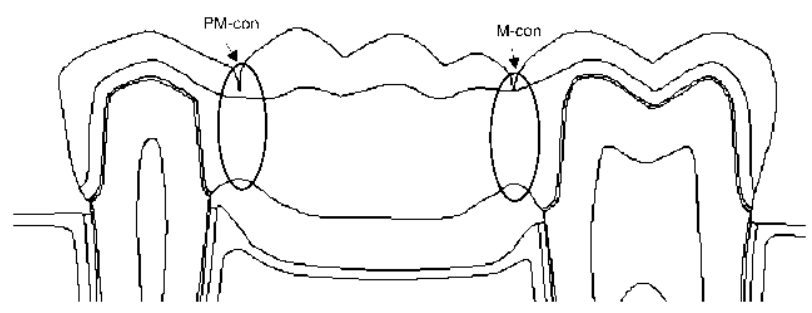

FIG. 5. Regions selected for the comparison of the FPD stress values. 
(A)
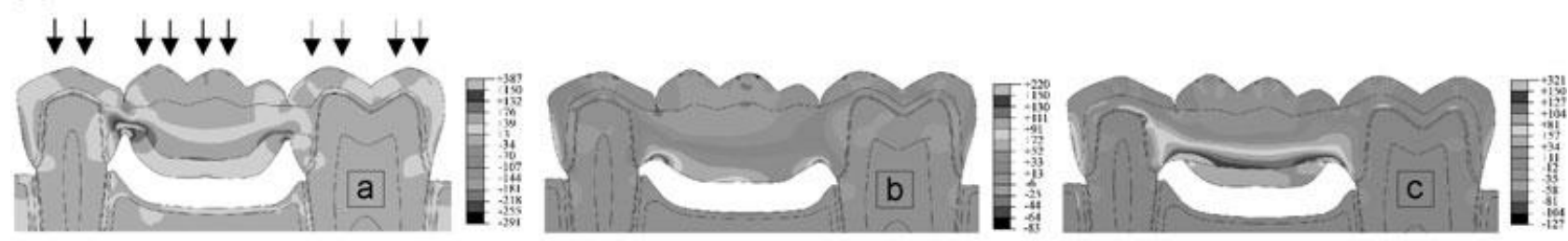

(B)
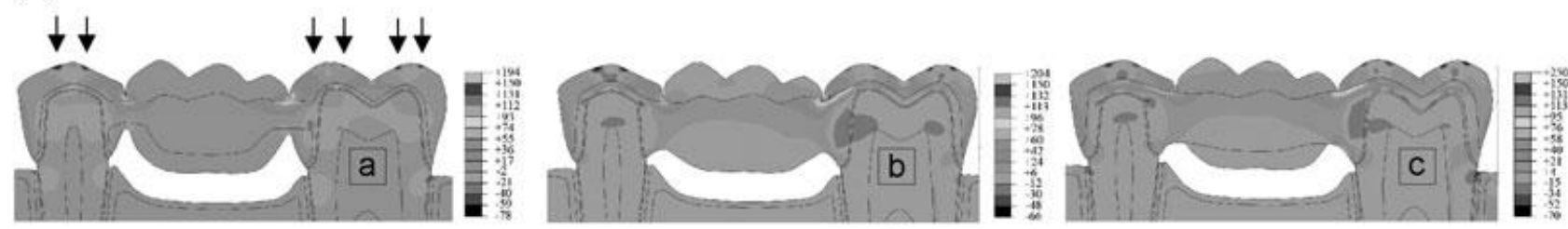

(C)
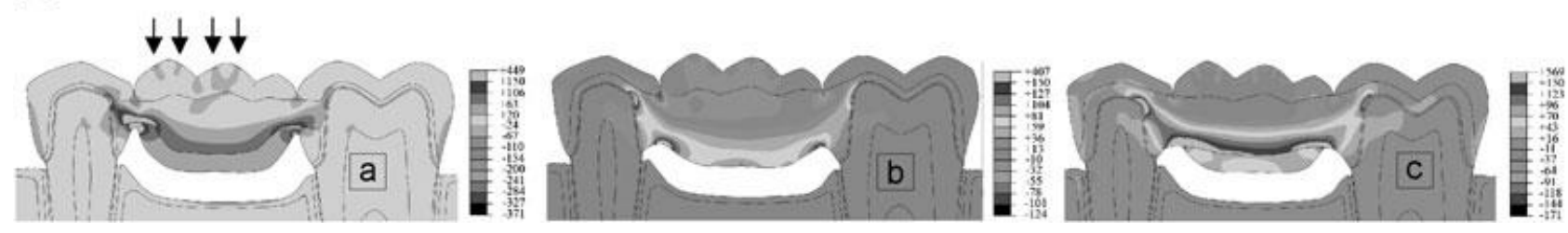

FIG. 6. (A) Stress distribution found when a physiologic load was applied. Models: (a) metal-ceramic FPD; (b) all-ceramic-O-FPD; and (c) all-ceramic-OC-FPD. (B) Stress distribution found when the abutment load was applied: (a) metal-ceramic FPD; (b) all-ceramic-OFPD; and (c) all-ceramic-OC-FPD. (C) Stress distribution found when the pontic load was applied. Models: (a) metal-ceramic FPD; (b) all-ceramic-O-FPD; and (c) all-ceramic-OC-FPD.

ceramic-OC-FPD (70 MPa) and 17\% higher than the value found for the all-ceramic-O-FPD (100 MPa). In the M-con, the all-ceramic-OC-FPD presented the lowest stress value $(86 \mathrm{MPa})$ followed by the allceramic-O-FPD (122 MPa) and by the MC-FPD $(134 \mathrm{MPa})$ that was 42 and $56 \%$ higher, respectively (Fig. 7A,B; Table 2).

\section{Pontic load}

When the loads were applied on the pontic (Fig. 6C), the highest stress values appeared on the connector areas between the abutments and the pontic. The stress distribution was very similar for the models submitted to the physiologic load, but the tensile stress values were higher and also extended to the metal or ceramic parts of the abutments. In the PM-con (Fig. 7A), the lowest tensile stress was found for the all-ceramic-OC-FPD (143 MPa). Both allceramic-O-FPD and MC-FPD presented the same results $(167 \mathrm{MPa})$ and they were $17 \%$ higher than the all-ceramic-OC-FPD. In the M-con (Fig. 7B), the results were quite similar for all models: all-ceramicO-FPD presented $108 \mathrm{MPa}$, MC-FPD $112 \mathrm{MPa}$, and all-ceramic-OC-FPD $114 \mathrm{MPa}$.

Other small areas of high stress concentration were identified in the proximal and marginal regions of the abutments.

\section{DISCUSSION}

Almost all laboratory studies pertaining to the mechanical behavior of an FPD use a load applied on the pontic central region $(2,9,10,13,15-17,22-25)$. The results found for these FEA and in vitro tests were the same. The maximum tensile stress was always found in the cervical embrasure of the connector, considering this region the weakest point of the prosthesis with the greatest potential of fractures, regardless of the material used. However, when the researchers go after clinical findings to support their results, they did not find them. Clinical experiment results show that the highest failure rate is related to biologic problems (6). Besides, the fracture occurs more often at the buccal face of the FPD and not at the connector region (1).

When an FPD is subjected to functional loading, the transferred forces give rise to stress and, in turn, to strain within the structure. Several factors can influence the resulting stress distribution, for example, the magnitude and direction of applied forces (15). The results of the present study showed a different stress distribution depending on the load configuration (Fig. 6A-C). When the load was applied on the pontic central region, a maximum bending stress in the FPD was induced (Fig. 6C). As 


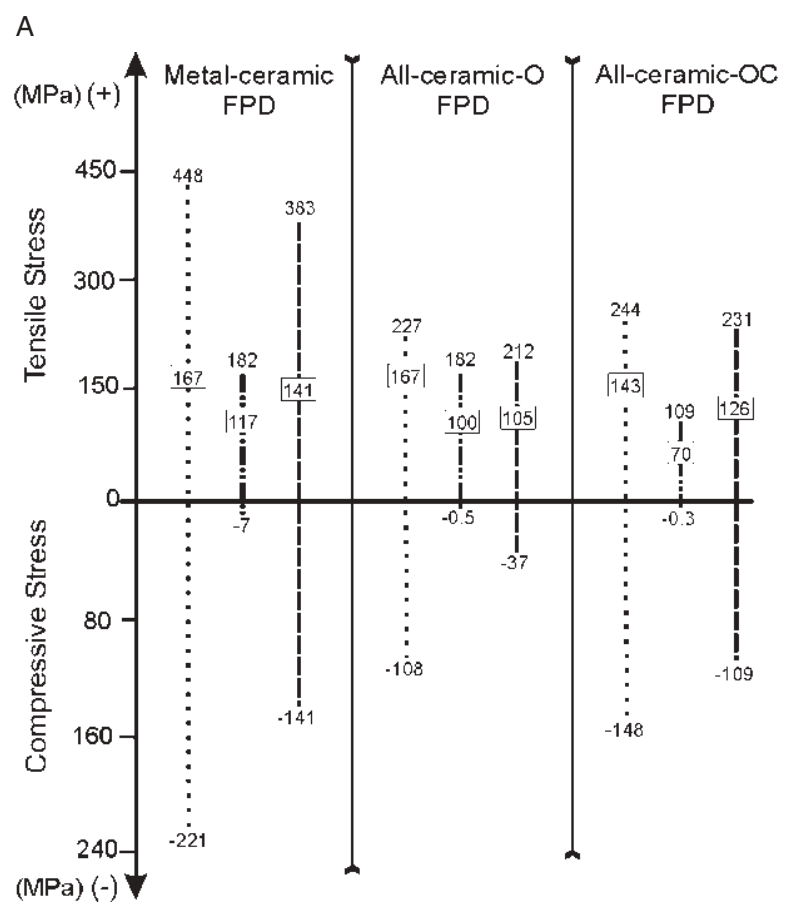

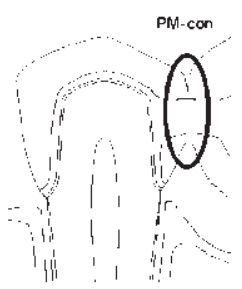

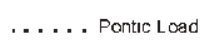

....... Abutment Load

--Z- Physiologic Load

$\square$ Meãn stress values

FIG. 7. (A) Maximum and mean stress values $(\mathrm{MPa})$ found in the premolar connector (PM-con) for each FPD model and loading condition. (B) Maximum and mean stress values (MPa) found in the molar connector (PM-con) for each FPD model and loading condition.

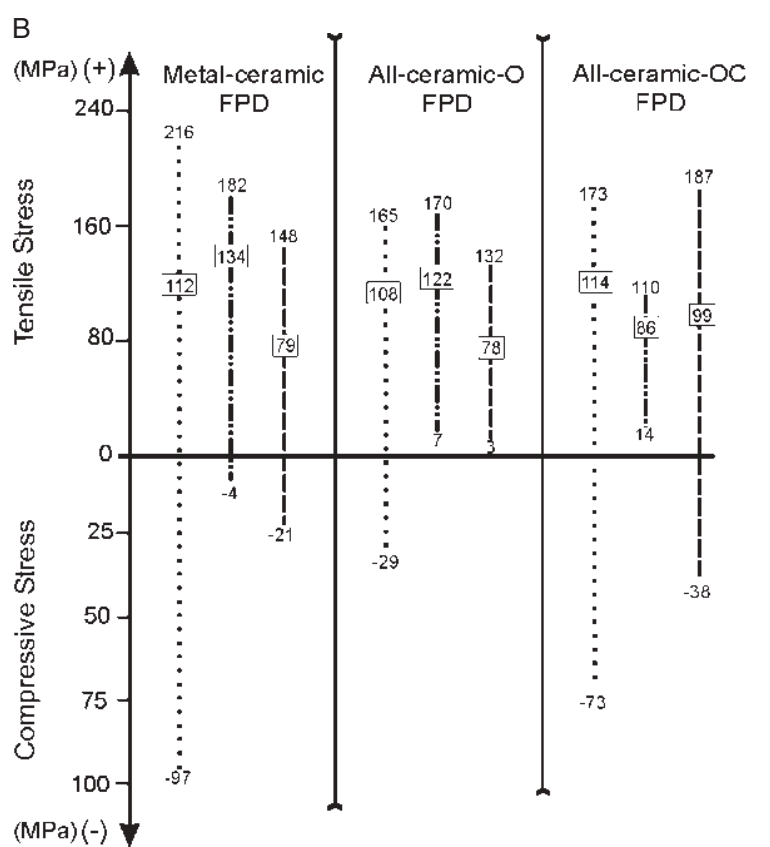

described by Crandall et al. (12), when the load is applied centrally on a beam, resting on two supports, it generates a nonuniform stress distribution, and the maximum tensile stress occurs between the support and the load. When a beam is submitted to a distributed load of the same magnitude, the stress will continue to be concentrated at the beam central region. However, the stress values will be lower than the values found when the load is applied centrally. Clini- cally, the central pontic load is avoided by the dentists. This type of load is only found in special situations, for example, when a rigid piece of food is chewed between the pontic and the antagonist tooth. Usually, the dentist distributes the load by the abutment teeth and the pontic. In some cases, the pontic was maintained in infra-occlusion, next to $80 \mu \mathrm{m}$, as the masticatory efficiency does not change and the antagonist tooth extrusion does not happen (18). In 
TABLE 2. Maximum and mean tensile stress values (MPa) found for each model with different loading conditions

\begin{tabular}{|c|c|c|c|c|c|c|}
\hline \multirow[b]{2}{*}{ Load } & \multicolumn{2}{|c|}{ Metal-ceramic FPD } & \multicolumn{2}{|c|}{ All-ceramic-O } & \multicolumn{2}{|c|}{ All-ceramic-OC } \\
\hline & PM-con & M-con & PM-con & M-con & PM-con & M-con \\
\hline \multicolumn{7}{|c|}{ Physiologic } \\
\hline Max & 383 & 148 & 212 & 132 & 231 & 187 \\
\hline Mean & 141 & 79 & 105 & 78 & 126 & 99 \\
\hline \multicolumn{7}{|c|}{ Abutment } \\
\hline Max & 182 & 182 & 182 & 170 & 109 & 110 \\
\hline Mean & 117 & 134 & 100 & 122 & 70 & 86 \\
\hline \multicolumn{7}{|l|}{ Pontic } \\
\hline Max & 448 & 216 & 227 & 165 & 244 & 173 \\
\hline Mean & 167 & 112 & 167 & 108 & 143 & 114 \\
\hline
\end{tabular}

the present study, the load distributed on all the working cusps showed a stress distribution quite similar to the pontic load, but with a smaller value of maximum stresses (Table 2). When the loads were applied only on the abutment teeth, the results showed that the stress patterns changed and the maximum stress values were found in the occlusal embrasure of the connector area, making it the most probable area to fail (Fig. 6B).

As many studies apply the load at the central part of the pontic, research was conducted to reach the best configuration for the connector area to support the tensile stress and not to fail. One more time, the results were not in accordance with the theoretic measure recommendations. Johanson et al. (14) and Ridwaan et al. (15) found results conspicuously lower. None of the studies reviewed $(10,14,15,19)$ tried to determine the optimal size of the connectors according to the length of the edentulous area and for each type of material constituting the FPD. The dental technicians state that they always try to optimize the connector dimensions, but the space between the abutment, pontic, and gingiva was the most determining factor (14).

Given the apparent underdimensioning of the connectors with reference to theoretic norms, a relatively more frequent occurrence of mechanically related failures in follow-up reports of FPDs in clinical service might be expected (6). Ridwaan et al. (15) believe that the reason for this not being the case may be that only overt manifestation of technical failures is usually included in the category. They believe that given the nature of flexure of a beam in response to loading, it is evident that a number of indirect effects can come about, some of which may present themselves as outcomes far from those of a typical design or dimensioning error. Actually, the loading condition applied in laboratory studies did not represent the clinical conditions.
The cervical and occlusal embrasures of the connectors act as a stress concentrator. The magnitude of local stress may increase significantly in embrasures with sharp geometry, as the curvature radius decreases in this region ( $\rho$ lower value at Eq. 1) (11). $\mathrm{Oh}$ and Anusavice (10) analyzed the effect of the radii of curvature at the connector on the fracture resistance of three-unit FPDs. They stated that as the radius at the gingival embrasure increased from 0.25 to $0.9 \mathrm{~mm}$, the mean failure load increased by $140 \%$. The radius of curvature at the occlusal embrasure had only a minor effect in their study, as they applied the load at the central region of the pontic.

Another aspect that has to be highlighted is the term "weak" used as a reference to the connector region that fails under an experiment (2,10,13-17). This term is not good for a scientific approach. A material can be called fragile or brittle when the fracture occurs without plastic deformation, and the material suddenly fractures. In contrast, when a material is called ductile, it means that the material suffers a plastic deformation before fracture (12). In both cases, the fracture will only happen when the load leads to the maximum stress value for failure. When the central pontic load is applied, the tensile stress values are higher in the connector region than in the other regions. However, the failure or fracture of the connector will occur only if these stress values are higher than the critical stress value (ultimate strength) of the material used for the FPD. The ultimate strength of ceramic materials is obtained from bending tests, and the fracture stress represents a statistic value obtained from the tests of many specimens (11).

The present study and all studies cited were realized with monotonic load. The material will fail when the maximum local stress reaches the ultimate strength of the material. However, clinically, the loads are cyclic and then fatigue failure criterion must be 
used. Under a fatigue approach, a subcritical crack growth must be considered in the regions submitted to maximum stress $(7,8)$. In some cases, the crack growth is so slow that other factors will lead to failure rather than the load. As described by Kamposiora et al. (16), the endurance limit for fatigue is approximately $40 \%$ of the ultimate strength. Then, the material could fracture under stress values much lower than the nominal fracture resistance of the material (the ultimate strength). That is due to fatigue crack growth, quite dependent on environment, mainly in the case of ceramic materials. When the cracks reach the critical value $\left(a_{\mathrm{c}}\right)$, associated with the material fracture toughness, failure will occur (7).

In the present study, the tensile stress analyzed in the premolar and molar connectors were the maximum and the mean values found for the region next to the embrasure tip. These values have to be analyzed carefully as they are reference values for comparison between the models developed for this study. Besides, different analyses should be done according to the loading condition applied to the models: monotonic or cyclic load.

In the monotonic load the fracture criteria used is that the tensile stress value in a region under analysis has to be higher than the ultimate strength of the material. This tensile stress value cannot be considered at only one point (finite element [FE] node) but in a characteristic distance from the crack (embrasure). This characteristic distance $\left(l_{0}^{*}\right)$ is a length related to the material microstructure, which is extended to a specific number of the material grains (11). For fracture to occur, the local tensile stress has to be higher than the critical stress to trigger the micromechanisms of fracture (brittle fracture) (7).

In the cyclic load, the fatigue process happens when a region (not an FE node or point) is submitted to a local field stress leading to favorable conditions for the initiation and growth of a crack (microstructure and stress dependent). The fracture will occur when the critical size of the crack $\left(a_{\mathrm{c}}\right)$ is reached. Therefore, in the present study, the mean tensile stress found in a region was used for the analyses of each model submitted to different loading conditions (7).

The stress values found in FE analyses cannot be considered as the absolute value for fracture, as the microstructure, the loading mode, and the local stress field are the parameters that have a strong influence on fracture. The FE stress values have to be carefully used to establish the fracture criteria or the failure of FE models. The stress values obtained in FE analyses are worth comparison when the model geometries are changed or new materials are used and if the loads are differently applied.
As ceramic materials are very susceptible to failure under tensile loading, all-ceramic bridges require even more stringent mechanical properties than those needed for metal-ceramic FPDs. According to some studies $(2,10)$, zirconia-based ceramics are the most appropriate to withstand the high tensile stress that occurs on multiunit bridges. In metal-ceramic FPD, the metal infrastructure presents the strength and the toughness to resist in the oral environment. Romeed et al. (17) stated that it is necessary to ensure that the greatest value of principal stress in all materials be less than the relevant critical value to rule out any possibility of material failure. Kamposiora et al. (16) analyzed the stress distribution in In-Ceram, gold, and Dicor FPDs. They found much lower stresses in In-Ceram FPDs, and concluded that the In-Ceram FPDs appear to be the most successful type of restoration.

The results found by Argereau et al. (13) showed that the strain observed along the mesio-distal direction is significantly more important than along the vestibule-lingual and occlusal-cervical directions. Therefore, the mesio-distal design of the FPD models can be appropriate, as the main purpose of the investigation is to compare the biomechanical behavior of the FPDs rather than report absolute values for displacements and maximum principal stresses.

Notwithstanding the sophistication of the FEA analyses, Romeed et al. (17) believe that the analyses suffer some limitations: materials are assumed to be isotropic, homogeneous, and linear elastic, despite the anisotropic nature of some structures and the presence of voids or cracks. Although the FE analyses allow the introduction of these parameters, the correct information about them for all tooth parts and all dental materials is not available.

\section{CONCLUSIONS}

Within the limitation of this 2D FEA study, the authors concluded that there is a significant change on the stress distribution and on the tensile stress values when the loading condition is changed. The best loading condition was found for the load applied only on the abutment teeth, as the stress values were lower and the stress distributions were more uniform. The connector regions presented the highest tensile stress values only when the load was applied at the center of the pontic. The sharp form of the FPD embrasures leads to high local stress values, with risk of fracture. Further tests have to be done using cyclic loads applied to simulate the real clinic condition. Besides, the results of each research have to be interpreted carefully for drawing the conclusions. 
Acknowledgments: The authors acknowledge the financial support by the Brazilian National Research Council (CNPq) and Telmo Roberto Strohaecker, Gabriel Tarnowsky, and Bruno Reis Antunes for their help in the solutions of the problems with the creations and analyses of models.

\section{REFERENCES}

1. Özcan M. Fracture reasons in ceramic-fused-to-metal restorations. J Oral Rehabil 2003;30:265-9.

2. Lüthy H, Filser F, Loeffel O, Schumacher M, Gauckler LJ, Hammerle $\mathrm{CH}$. Strength and reliability of four-unit all-ceramic posterior bridges. Dent Mater 2005;21:930-7.

3. Olsson KG, Furst B, Andersson B, Carlsson GE. A long-term retrospective and clinical follow-up study of In-Ceram Alumina FPDs. Int J Prosthodont 2003;16:150-6.

4. Karlsson S. A clinical evaluation of fixed bridges, 10 years following insertion. J Oral Rehabil 1986;13:423-32.

5. Palmqvist S, Swartz B. Artificial crowns and fixed partial dentures 18 to 23 years after placement. Int J Prosthodont 1993;6:279-85.

6. Lindquist E, Karlsson S. Success rate and failures for fixed partial dentures after 20 years of service: part I. Int J Prosthodont 1998;11:133-8.

7. Suresh S. Fatigue crack growth in brittle solids. In: Suresh S, ed. Fatigue of Materials, 2nd Edition. Cambridge, UK: Cambridge University Press, 1998;383-407.

8. Bradt RC, Evans AG, Hasselman DPH, Lange FF. Fracture Mechanics of Ceramics: Microstructure, Methods, Design, and Fatigue. New York, NY: Plenum Press, 1986.

9. Randow K, Glantz PO, Zoger B. Technical failures and some related clinical complications in extensive fixed prosthodontics. An epidemiological study of long-term clinical quality. Acta Odontol Scand 1986;44:241-55.

10. Oh WS, Anusavice KJ. Effect of connector design on the fracture resistance of all-ceramic fixed partial dentures. J Prosthet Dent 2002;87:536-42.

11. Callister WD. Materials Science and Engineering: An Introduction, 5th Edition. New York, NY: John Wiley \& Sons, 2000.

12. Crandall SH, Lardner T, Dahl NC. An Introduction to the Mechanics of Solids, 2nd Edition. New York, NY: McGrawHill, 1978.
13. Argereau D, Pierrisnard L, Barquins M. Relevance of the finite element method to optimize fixed partial denture design. Part I. Influence of the size of the connector on the magnitude of strain. Clin Oral Invest 1998;2:36-9.

14. Johanson M, Mosharraf S, Karlsson S, Carlsson GE. A dental laboratory study of the dimensions of metal frameworks for fixed partial dentures. Eur J Prosthodont Restor Dent 2000;8:75-8.

15. Ridwaan O, Abduljabbar T, Al-Ali K, Smyth M, El-Agouri R. Dimensions of metal framework components of metal-ceramic fixed partial dentures constructed in a dental school setting. Quintessence Int 2004;35:820-5.

16. Kamposiora P, Papavasiliou G, Bayne SC, Felton DA. Stress concentration in all-ceramic posterior fixed partial dentures. Quintessence Int 1996;27:701-6.

17. Romeed SA, Fok SL, Wilson NHF. Finite element analysis of fixed partial denture replacement. J Oral Rehabil 2004;31: 1208-17.

18. Lundgren D, Falk H, Laurell L. Influence of number and distribution of occlusal cantilever contacts on closing and chewing forces in dentitions with implant-supported fixed prostheses occluding with complete dentures. Int J Oral Maxillofac Implants 1989;4:277-83.

19. Koutayas SO, Kern M, Ferraresso F, Strub JR. Influence of design and mode of loading on the fracture strength of allceramic resin-bonded fixed partial dentures: an in vitro study in a dual-axis chewing simulator. J Prosthet Dent 2000;83: $540-7$.

20. Shillinburg HT, Hobo S, Whitsett LD, Jacobi R, Brackett SE. Fundamentals of Fixed Prosthodontics, 3rd Edition. Chicago, IL: Quintessence Publishing Co., 1997.

21. Rees JS, Hammadeh M. Undermining of enamel as a mechanism of abfraction lesion formation: a finite element study. Eur J Oral Sci 2004;112:347-52.

22. Toparli M, Aykul H, Aksoy T. Stress distribution associated with loaded acrylic-metal-cement crowns by using finite element method. J Oral Rehabil 2002;29:1108-14.

23. Ibrahim A, Sertgöz A, Ekici B. Influence of occlusal forces on stress distribution in preloaded dental implant screws. J Prosthet Dent 2004;91:319-25.

24. Imanishi A, Nakamura T, Ohyama T, Nakamura TD. Finite element analysis of all-ceramic posterior crowns. J Oral Rehabil 2003;30:818-22.

25. Lanza A, Aversa R, Rengo S, Apicella D, Apicella A. 3D FEA of cemented steel, glass and carbon posts in a maxillary incisor. Dent Mater 2005;21:709-15. 